\title{
Models and Methods:
}

\section{The Tools of Library Networking}

Several models and methods applicable to university library networks are discussed as tools to increase understanding of cause and effect relationships in these complex organizations. Collection of data by unobtrusive measures and display of information by graphic techniques are briefly described. The utility of the interventionist method, organization development techniques, and pilot projects is outlined. Levinson's organization diagnosis techniques and Meier's communications model depict university libraries as stressed organizations. Other models applied to the university library context include a network model, Sloan's exchange model, Thompson's organization action model, and Saeger's vendor model.

M GANIZATIONS is one of the great challenges of this century. Lack of sufficient understanding of the cause and effect relationships operating in large complex organizations can demonstrably lead to such difficulties as the energy crisis, the inflation crisis, the unemployment crisis. Library networks will scarcely cause major crises in themselves, but networks in difficulty can affect the lives and fortunes of hundreds of people and will involve institutions which represent large capital-intensive investments of communities, cities, states, or universities in the range of millions of tax or gift dollars. Understanding cause and

Thomas F. Parker is a library management consultant and served as project director of the Library Study Project for the libraries of the California Institute of Technology; University of California, Los Angeles; and the University of Southern California. This project was supported by the National Science Foundation (Grant GN33010). effect relationships in library networks is an undertaking worthy of considerable attention. Effective management of these enterprises is absolutely dependent on accurate knowledge of how library networks operate, the nature of their components and functions, the effectiveness of development methods, and which methods operate at least cost in human stress and scarce dollars.

Fortunately for those who seek understanding of library networks a number of models and methods are available to increase understanding of cause and effect relationships and workable development approaches.

The Library Study Project-a feasibility study of library cooperation among the libraries of the California Institute of Technology; the University of California, Los Angeles; and the University of Southern Californiahad an opportunity not only to survey available models and methods but to assess their worth in actual field experience. Among the models utilized were 
a network model, the exchange model, the organization action model, the communications model, and the vendor model. Useful methods employed included graphic data display, the interventionist method, organization development, organization diagnosis, the use of pilot projects as change tools, and unobtrusive measures for data collection. The models are all narrative-English-language, nonmathematical models. The methods have all been applied in the field of management but have seldom, if ever, been utilized in an academic library environment.

\section{Collection and Display of Data}

One of the most challenging tasks facing the manager or analyst of large complex organizations is that of making the organization observable. The problem has been effectively formulated in the field of urban analysis, and various methods are employed to make urban systems observable. Library administrators have long used a variety of personal methods to keep track of the variegated operations of their organizations, including various reporting structures, hierarchical staff meetings, and disjointed incrementalism. Multiple operationism is frequently resorted to in a recognizable pattern identified as a management "style."

The Library Study Project faced the problem of making three large, disparate libraries observable within the constraints of limited project staff, project schedule limitations, and the necessity of avoiding disruption of library operations. Data collection was carried out using the unobtrusive measures techniques formulated by Eugene Webb and others at Northwestern University. ${ }^{1}$ The approach assumes that the environment is open, that multiple operationism must be used to avoid methods that share the same weaknesses, and that the analyst is always dealing with approximations to knowledge. Sources of mea- sure invalidity are explicitly recognized. The approach of choice utilizes simple observation, contrived observation, and physical traces that include erosion and accretion, running records, and episodic records. The Library Study Project collected all publicly available library information handouts, library guides, and various public reports. Limited use was made of internal reports, other than annual ones, although other reports were freely made available by the libraries. In addition, the project collected student newspapers, publicity releases, and local newspaper clippings on a systematic basis. The publicity releases carried valuable information on substantive changes occurring in the universities and the libraries, as did the newspaper clippings. Student newspapers carried invaluable reports of official and unofficial events, including campus controversies and any problems encountered in using the libraries. Project staff employed simple observation techniques in interviewing library personnel in the dozens of library units encompassed in the study.

The amount of data collected during the life of the project was substantial. To increase utility of the material, the information collected was summarized and displayed in graphic fashion. Graphic data display is a simple extension of the familiar use of maps, flow charts, and organizational charts. However, in the project graphic display was used as a deliberate tool in organizational problem solving.

The project employed a wide range of graphic display options, including circle graphs, bar graphs, symbolic graphs, maps, and symbolic libraryprocess flow charts devised by the project. Bar charts were created for operating statistical data. Hours of library operation were shown, and unit and service locations and library-to-library unit interactions were mapped. Administrative organization was charted. Library 
staff size and personnel distribution were developed from analysis of staff lists.

\section{Network FeasibiLITY}

The potential for a library network among the three libraries was explored using the interventionist method, organization development techniques, and a variety of pilot projects.

The interventionist method has been formulated by Chris Argyris at Yale University, one of the foremost authorities on organizational behavior in the country. ${ }^{2}$ The method focuses on three tasks: generating valid and useful information for the client systems, helping the clients make free and informed choices among their options, and generating firm client commitment to their choices.

The interventionist aims at aiding the client system in collecting and communicating valid and accurate information about the realities of the situation, without distortions from the biases and defenses of the client systems, other decision makers, or the interventionist. The interventionist works with the client systems to generate free choice, i.e., choice made with minimal internal defensiveness, based on valid information related to the client's main goals and needs and incorporating a realistic, challenging level of aspiration. The interventionist strives to represent the whole client system in his efforts, not the point of view of any group or individual, or his own.

Once free choice has been made, the last task is that of aiding the client systems in developing internal commitment to the path selected. Anyone embarking on a new venture is beset by doubts, and so are library administrators. Therefore, the interventionist provides support for the clients' free choice. When these three tasks have been completed, the interventionist then terminates association with the client systems, which have been strengthened by the intervention. The contrast between the interventionist method and the more frequently encountered "selling" of system change is striking, since the interventionist method is devoid of manipulative aspects.

\section{Organization Development}

In addition to the interventionist method, the Library Study Project utilized techniques of the field of organization development, or OD.

Organization development is a relatively new field in the area of management. It grew out of work done at Case Western Reserve University, Harvard University, Massachusetts Institute of Technology, University of California at Los Angeles, and Yale University. Some of the pioneers in developing the field include Chris Argyris, Richard Beckhard, Kenneth Benne, Warren Bennis, Robert Blake, Jane Mounton, and Herbert Shepard. An excellent summary of the field has been published by French and Bell. ${ }^{3}$

Organization development focuses on organization behavior interventions designed to build action teams. In OD work considerable attention is paid to role and goal clarification, interpersonal and interunit relationships and conflicts, client underutilization of each other as resources, and the processes of communication, decision making, and task allocation. Typically an organization development effort is based on an action-research model that begins with data gathering and situation assessment and moves on to feedback to the client systems, followed by discussions and work on the feedback and on emerging or updated information, joint action planning, action, and further data gathering and feedback, with reiteration of the cycle. The action-research model was prominent in the activities of the $\mathrm{Li}$ brary Study Project. Early in the study the project team took on the role of a 
neutral buffer operating in a constant information-feedback mode. In the two-year life of the project, team members held over 400 meetings with librarians, library staff, and university staff and administrators.

\section{Pilot Projects in Network DEVELOPMENT}

To enhance the information being developed and fed back to the participating libraries, a series of pilot projects were developed and implemented. For libraries to make free and informed choices on the feasibility of resource sharing, it is desirable for them to have first-hand information on the risks, potentials, and benefits. Pilot projects provide opportunities for libraries to effectively explore mutual arrangements, the impacts, benefits, and difficulties in a controlled, safe, but real-world environment. In the feasibility study, pilot projects were developed, implemented, and monitored on the basis that they could be terminated at any time, without prejudice, by any participant who wished to withdraw. The pilot projects included a delivery and passenger service, which proved to be a useful interlibrary link, and test utilization of teletype and telecopiers, which were not successful as such, but were useful to the libraries as additional opportunities for joint interaction and decision making.

\section{Libraries as Stressed Organizations}

Large academic libraries are no different in many aspects from other large, complex organizations. In the course of their development they encounter stressful conditions with which they must cope to survive. Assessment of the stress levels in organizations is as important to library network development as the activities of a doctor examining the health of a football team are to team performance. If one team member is severely stressed, the team may inadvertently place an overload on that position (or node in a network), and team failure may result.

A technique for assessment of organizational stress has been developed by Harry Levinson at Harvard University. ${ }^{4}$ Levinson divides activities that organizations undertake as stress responses into adaptive and maladaptive categories. $\mathrm{He}$ classifies some 110 specific activities as normal, exaggerated normal, maladaptive, disruptive, or self-destructive. The Library Study Project found that none of the three libraries studied was completely free from activities in the range from normal through disruptive.

In addition to Levinson's work, the communications model of a university library developed by Meier identifies communications overload stress responses and the consequences. ${ }^{5}$ Meier found that severe tests of the library resulted in spatial consequences, status structure modifications, changes in the communications structure, and alterations in the value and relationships structures of the library. Again, the project team found that all three libraries evidenced severe stress responses. It is clear from the standpoint of large organizations or the viewpoint of libraries as communications systems that academic libraries are likely to show substantial scars of severe stress.

\section{Models of Libraries in Action}

Besides Meier's model, the Library Study Project utilized four other sociological nonquantitative models to enhance understanding of the complex cause and effect relationships at work in university libraries.

A network model was formulated to provide insight into the structure of library-to-library interactions. Several formulations of the network model are available in library literature. The model synthesized by the Library Study Project viewed a library network as having five basic components: resources (books, 
periodicals, other library materials, and staff expertise), directories to the resources (card catalogs, printed catalogs, holdings lists, in-process files), communications (telephones, teletype, material delivery, passenger service), users (faculty, graduate students, undergraduates), and management (consortium management, library administrations, committees, task teams).

In the course of the feasibility study the project team paid considerable attention to the skills required for successful library interaction. The team found that a library network clearly requires a specialized and not widely recognized set of skills that are boundaryspanning in nature. These boundaryspanning skills are different in type from the skills utilized inside a single, even multiunit, library. The skills involve the ability to carry out effectively the interactive coordination of network activities; regular information exchange; development of an understanding of each member library's policies, procedures, and problems in a nonjudgmental fashion; and development of an understanding of each member library's larger organization, its parent campus, and campus administrative policies and problems. Boundary-spanning skills also include a capability to accommodate role changes: former rivals are now suddenly to be treated as part of the home team. Absence of an adequate level of boundary-spanning skills will prevent effective ongoing network operation.

The study team analyzed the management requirements of a library network. The findings indicate that network management is unexpectedly complex. Library network management includes operations management, service supplier management, service user management, and service broker management functions; and these are usually dispersed. Network operations management is required for network facilities which must be obtained and installed and for protocols which are developed for operation, maintenance, and feedback on stability. Network management must identify service suppliers, assess their capabilities, and define the type of service they are willing to supply. Potential network users must be identified and frequently aided in effective use of network services available to meet their needs. The service broker function must be performed to bring potential users and suppliers together and assist them in making arrangements for service exchange over the network. In library networks, management functions may be dispersed or concentrated, performed entirely by member libraries, by a central group, or by some combination.

\section{EXCHANGE MODEL OF LIBRARY RESOURCE SHaring}

The exchange model of library resource sharing developed by Sloan was found to be of particular use in assessing the readiness of libraries to form a network. Sloan based her model on work by Thompson (described below), with modifications drawn from smallgroup interaction and coalition formation theory. ${ }^{6}$ The exchange model identifies the prerequisites of library resource exchange, discusses the determinants of exchange (range, direction, degree of dependency, structure of units, and domain consensus), and develops five indices of readiness to cooperate. In these the degree of domain consensus is seen as crucial, with important influences emanating from the existing motivation to coalesce, the amount and type of resources relevant to the exchange, the values placed on alternative expectations, and the influence of nonutilitarian strategy choices. These last include prestige, influence on the group, power or leadership elements, and desire to expand domain. The Library Study Project found that the exchange model cast important light on several aspects of cooperation potential, providing valida- 
tion or indicating the need for further checking of project hypotheses on potentially fruitful areas of cooperation.

\section{The Organization Action Model}

The organization action model developed by James D. Thompson proved to be quite applicable to university libraries. $^{7}$ Thompson's model regards complex organizations as operating a certain type of technology (which can be manual) to perform an instrumental task. The organization is made up of a set of components (institutional, managerial, core technology, and boundaryspanning), each with specific functions, problems, and a finite range of coordination options. The organization performs its instrumental task in an interactive task environment containing suppliers, clients, competitors, and regulatory groups. The organization faces external and internal contingencies and constraints that threaten the organization's survival and must be managed. To manage these threats the organization develops internal and external interaction strategies to achieve homeostasis in the face of environmental fluctuation. The organization is dependent on human discretion to operate the core technology, span the boundaries, manage the activities, and implement the survival strategies. To obtain this crucial human element the organization negotiates inducement-contribution contracts with individuals with the necessary skills or capabilities.

The Library Study Project found that the organization action model provides an effective overview of university libraries operating in complex environments. The model supplied clear definition of the similarities and differences of the libraries studied. The model has great potential for supplementing the experience and intuition of library administrators by defining the appropriate internal structures to meet external con- tingencies, external interaction strategies, and effective internal coordination as required by circumstances. The model will be useful in predicting crises in the external environment, in identifying areas in which the library is vulnerable, and in predicting the impact of proposed changes in library policies and procedures.

\section{The Vendor ModeL}

In addition to the models identified and retrieved from the literature on organizational behavior, one model was developed inside the project. The project's senior systems analyst, JoAnn Saeger, successfully formulated the vendor model, which defines the complex interaction that takes place between a vendor and a customer. ${ }^{8}$ The model describes four time-sequenced stages: initial contact, test contract negotiation, contract implementation, and contract evaluation. The model identifies the key issues and key individuals at each stage and predicts individual behavior as the sequence progresses. The model is particularly accurate in predicting the behavior of the contact person inside the customer (read library) organization, with goal ranges, task types, and positions at contract evaluation time. The model also outlines the main tasks of both the vendor and customer organizations, with implications for customer responsibility. The model highlights the crucial role that must be played by the library systems analyst as intermediary, with analytical, specification writing, legal, and program-management functions. The vendor model will be useful in procurements of any system of such complexity that evaluation is difficult (e.g., a computerized acquisitions or circulation system).

\section{SUMMARY}

The Library Study Project was fortunate in having the opportunity to iden- 
tify, examine, and apply a number of organizational behavior methods and models in a real-world environment. Unobtrusive measures, graphic data display, organization development methods, pilot projects, and stress analysis are effective tools for network development or improvement. The network model, the exchange model, the organization action model, and the communications and vendor models contribute substantially to an understanding of the vital cause and effect relationships in the complexities of library networks.

\section{REFERENCES}

1. Eugene Webb and others, Unobtrusive Measures: Non-Reactive Research in the Social Sciences (Chicago: Rand-McNally, 1966).

2. Chris Argyris, Intervention Theory and Method: A Behavioral Science View (Reading, Mass: Addison-Wesley, 1970).

3. Wendell L. French and Cecil H. Bell, Jr., Organization Development: Behavior Science Interventions for Organization Improvement (Englewood Cliffs, N.J.: Prentice-Hall, 1973).

4. Harry Levinson, Organization Diagnosis
(Cambridge, Mass.: Harvard Univ. Pr., 1972).

5. Richard L. Meier, "Information Input Overload," Libri 13:9-44 (1963).

6. Elaine F. Sloan, "Toward an Understanding of Library Cooperatives as Organizations" (ERIC, 1970). ED 047752.

7. James B. Thompson, Organizations in Action (New York: McGraw-Hill, 1967).

8. JoAnn Saeger and Thomas F. Parker, "A Bridge between Two Worlds: The Interaction between a Library and a Vendor of Advanced Technology" (unpublished). 